\title{
Measurement of indoor radon concentration and actual effective dose estimation of schools at high radon area in Korea
}

\author{
B.U. Chang ${ }^{1,2}$, Y.J. Kim ${ }^{1,2}$, M.H. Song ${ }^{1}$, G.H. Kim², \\ S.Y. Jeong ${ }^{1,2}$ and K.W. Cho ${ }^{1,2}$ \\ ${ }^{1}$ Korea Institute of Nuclear Safety, 34 Gwahak-ro, Yuseong-gu, 305-338, \\ Daejeon, Republic of Korea \\ ${ }^{2}$ University of Science and Technology, 113 Gwahak-ro, Yuseong-gu, 305-333, \\ Daejeon, Republic of Korea
}

\begin{abstract}
On the basis of previous survey results of indoor radon for schools, detailed radon survey was conducted in one hundred three selected schools in Korea during the second semester in 2010. According to the results of effective dose assessment due to inhaled radon of during occupancy time, fourteen schools for requiring urgent mitigation action were selected, and recommended to the government.
\end{abstract}

\section{INTRODUCTION}

In 2008-2009, a new radon survey in public buildings (local governmental offices and elementary schools) was conducted in Korea [1]. This survey was the fourth national radon survey in Korea and the average indoor radon concentration in some elementary schools were found to be over $300 \mathrm{~Bq} \cdot \mathrm{m}^{-3}$, which is the new recommended reference level in dwellings of the Statement of ICRP on radon in November 2009 [2]. This result was released into the public through the mass media, and became a pubic concern as a possibility of high exposure of young students in schools was raised. However, occupancy time of the students is relatively short compare with that of dwellings. They generally stay during day time and are exposure to relatively low indoor radon concentration, which means that actual dose level by exposure to radon may be lower than the estimated dose calculated from the average radon concentration. The passive alpha-track detectors, commonly used for indoor radon survey to provide only average concentration during the exposure period, is not adequate to evaluate the actual effective dose for students or daytime workers in schools. In addition, due to the over estimation by measurement of only average radon concentrations obtained from passive detectors, it is possible that the unnecessary or excessive action to determine radon mitigation can be conducted. Therefore, in order to determine the real necessity of mitigation (including installing active radon removal system) for schools, this study was carried out by the request of the Ministry of Education, Science and Technology (MEST).

\section{SELECTION OF SCHOOLS AND SURVEY METHODS}

One hundred three schools found with the high indoor radon concentration were selected on the basis of previous survey results (fourth national radon survey [1] and unpublished preliminary survey results accomplished by the Local Education Authority). The locations of schools for sampling were shown in Figure 1. To estimate actual effective dose due to radon inhalation during working time, the radon concentration was continuously measured and recorded with the average of every 30 minute's concentration using twelve different active radon detectors (9 RAD7s, Durridge co., USA; 2 RTM2200s, SARAD co., Germany; and, 1 Alpha Guard, Genitron Instruments GmbH., Germany) during one 


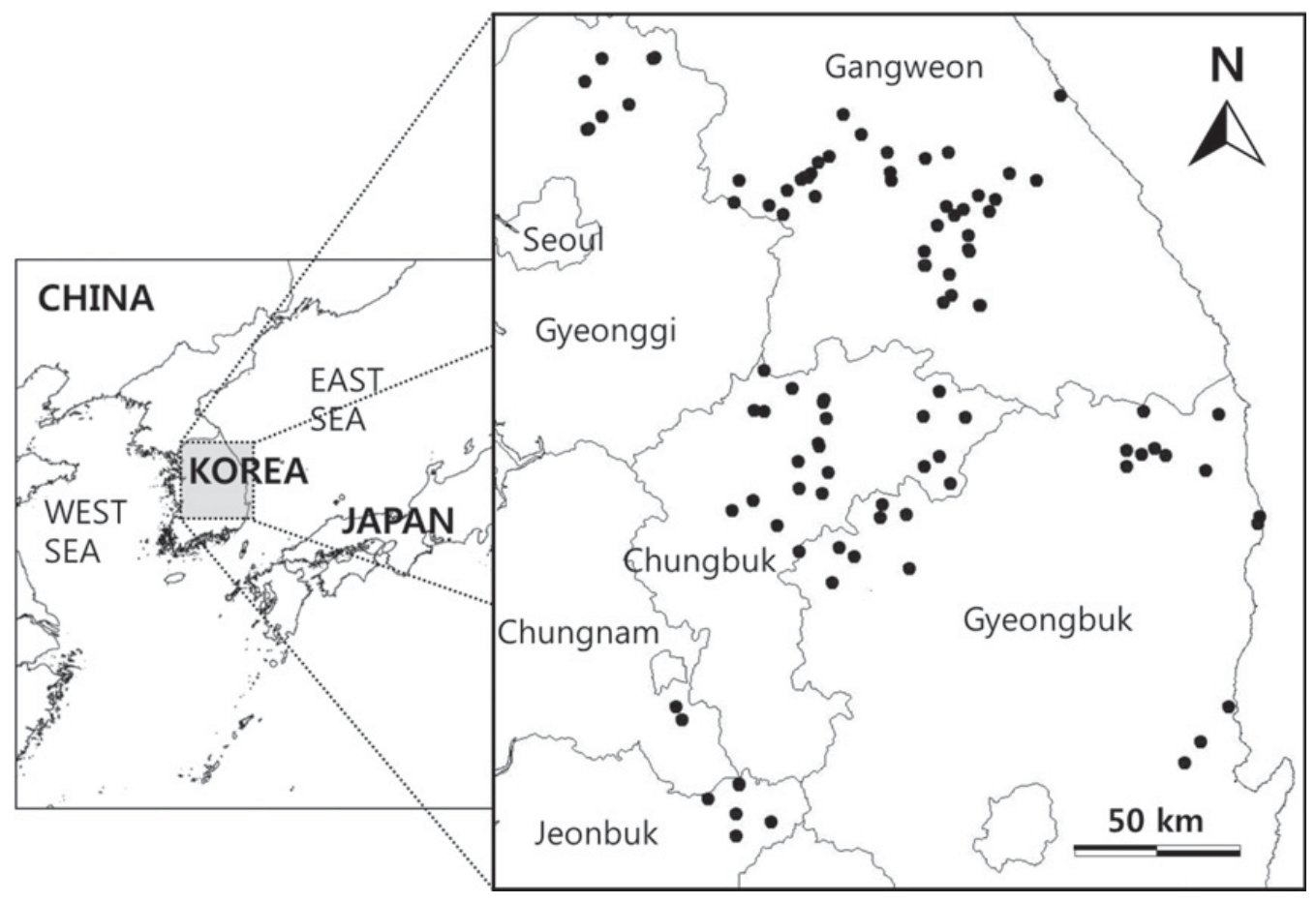

Figure 1. Location Map of one hundred three schools.

week in teacher's office of each school. The continuous radon measurement was carried out only at teacher's office to avoid interrupt of measurement by curious students. For the purpose of quality control for continuous radon measurement, one alpha-track detector (Raduet ${ }^{\circledR}$, Radosys co., Hungary) was installed at the same point for the same period. Figure 2 shows the comparison between the indoor radon concentration obtained from the alpha-track detectors and the continuous measurements during a week. Two measurement results show good linearity. In addition, in order to measure average radon concentration during semester and calculate the effective dose of semester, Raduet ${ }^{\circledR}$ alpha-track detectors were installed at the same point of continuous radon measurement in teacher's office and classroom during second semester (from August to December). The continuous measurement during a week for each school was carried out sequentially during second semester in 2010 (from August to November). After collecting the distributed Raduet ${ }^{\circledR}$, CR-39 chips in the detectors were taken out and chemically etched with a $6.25 \mathrm{M} \mathrm{NaOH}$ solution at $90^{\circ} \mathrm{C}$ for 4.5 hours and alpha tracks were counted with an automatic track analysis system (RSV-6, Radosys Co., Ltd, Hungary).

\section{RESULTS AND DISCUSSION}

Main inflow source of radon was radon-rich air from the surrounding soils and rocks which is introduced into the indoor through the bottom floor of the room. Ventilation is more difficult in cold season (autumn and winter); the indoor radon concentration in cold season is higher than that in warm season (spring and summer). Temperature differences between indoors and outdoors produce a pressure gradient across the building shell which is called the stack effect. This driving force is particularly important during cold season, since it induces the inward flow of radon-rich air from surrounding soil to the inside of house [3]. Especially in public buildings such as schools, the indoor radon concentration is increasing rapidly during night, because the building is tightly closed during off duty time (night and weekend). 


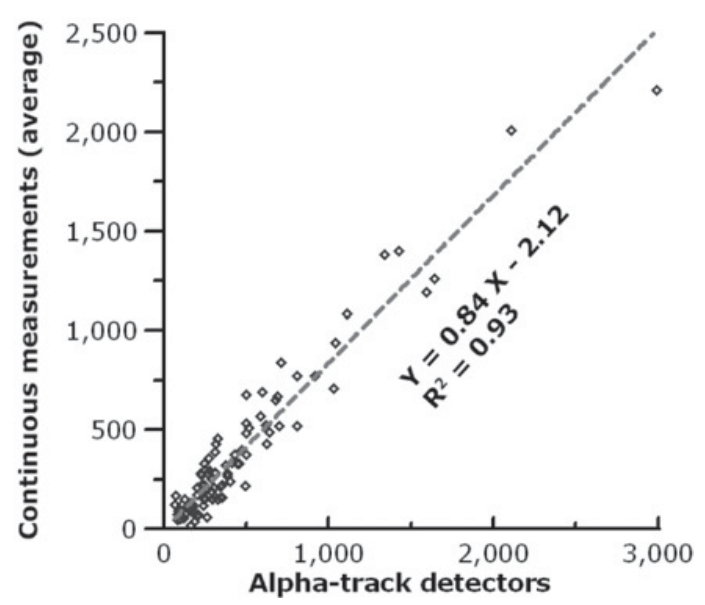

Figure 2. Comparison the average indoor radon concentration obtained between the alpha-track detectors and the continuous measurements during a week.

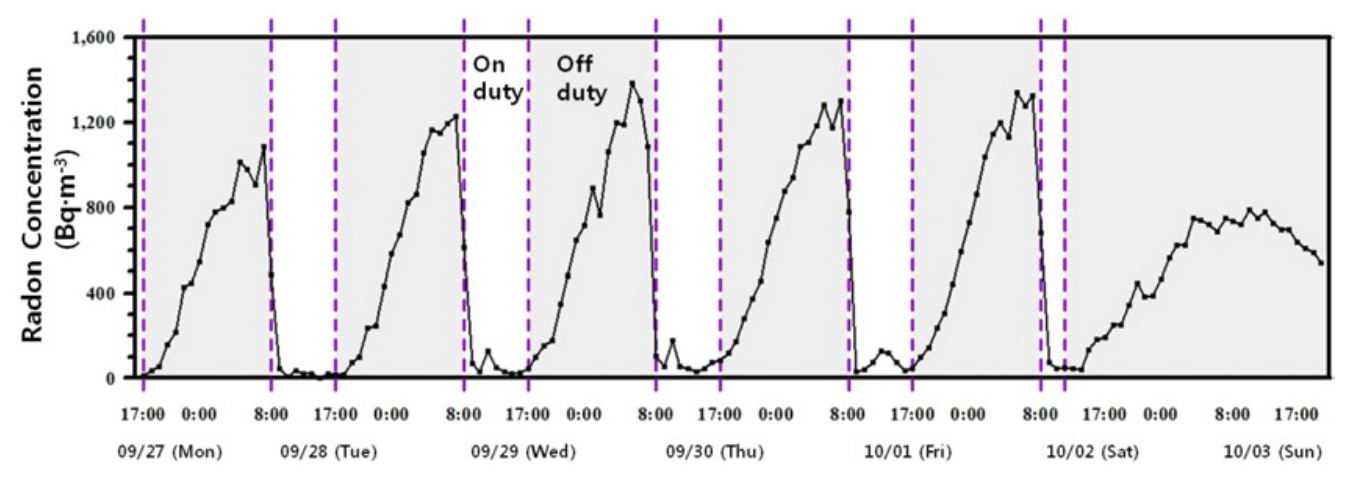

Measurement Day and Time (Suwhoi Elementary School, Chungbuk)

Figure 3. An example showing the daily variation of indoor radon concentration depending on the air ventilation using continuous radon monitor (RAD7) in schools.

Figure 3 shows a typical example of the variation of indoor radon concentration during a week using continuous radon monitor. Usually, the differences in radon concentration between on and off duty time are significant in the schools, which show high average indoor radon concentration.

The variation patterns of indoor radon concentration between on and off duty time in each school were significantly different. It is predicted that these variation patterns are due to the characteristics of building such as construction time, ventilations habitants, building materials, bottom floors status, and temperature gradient between indoor and outdoor, and others. Effective dose was assessed using the dose calculation method given in ICRP 65 (Equation (1)) [4]. On duty time weighted conversion factors $\left(\mathrm{C}_{o}\right)$ were calculated based on a week continuous monitoring result of schools, respectively. The residential effective dose was evaluated for the students and teachers during the second semester by using these conversion factors and average indoor radon concentration obtained by alpha track detector retrieved from classroom and teacher's office room in each school (Equation (2)).

$$
E_{\mathrm{d}}=R_{\mathrm{c}} \times R_{\mathrm{t}} \times E_{\mathrm{f}} \times D_{\mathrm{c}}
$$

where $E_{\mathrm{d}}$ is the effective dose, $R_{\mathrm{c}}$ the radon concentration, $R_{\mathrm{t}}$ the residence time, $E_{\mathrm{f}}$ the equilibrium factor between radon and its decay products and $D_{\mathrm{c}}$ the dose conversion coefficient.

$$
E_{\mathrm{od}}=E_{\mathrm{d}} \times C_{\mathrm{o}}
$$


Table 1. The range of average indoor radon concentration of schools and the range of the effective dose of on duty time during the second semester.

\begin{tabular}{|c|c|c|c|c|c|}
\hline \multirow[b]{3}{*}{ Province } & \multicolumn{3}{|c|}{$\begin{array}{l}\text { The range of average indoor radon } \\
\text { concentration of schools }\left(\mathrm{Bq} \cdot \mathrm{m}^{-3}\right)\end{array}$} & \multicolumn{2}{|c|}{$\begin{array}{l}\text { Effective dose of on duty time during } \\
\text { the second semester }(\mathrm{mSv})\end{array}$} \\
\hline & \multirow{2}{*}{$\begin{array}{l}\text { the second } \\
\text { semester } \\
\text { (Raduet) }\end{array}$} & \multicolumn{2}{|c|}{$\begin{array}{l}\text { One week average using } \\
\text { continuous monitor }\end{array}$} & \multirow[b]{2}{*}{$\begin{array}{l}\text { Teachers } \\
\text { (average) }\end{array}$} & \multirow[b]{2}{*}{$\begin{array}{l}\text { Students } \\
\text { (average) }\end{array}$} \\
\hline & & total & $\begin{array}{c}\text { on duty time } \\
\text { only }\end{array}$ & & \\
\hline Gangweon (43) & $26-1,130$ & $42-2,000$ & $30-1,060$ & $0.10-2.15(0.53)$ & $0.06-1.50(0.42)$ \\
\hline Chungbuk (23) & $30-2,650$ & $38-7,210$ & $15-4,490$ & $0.06-5.81(0.55)$ & $0.05-4.51(0.42)$ \\
\hline Gyeongbuk (20) & $55-1,390$ & $63-2,210$ & $11-1,210$ & $0.04-2.77(0.35)$ & $0.03-3.04(0.41)$ \\
\hline Gyeonggi (8) & $58-438$ & $39-699$ & $36-423$ & $0.18-1.31(0.59)$ & $0.13-0.47(0.24)$ \\
\hline Jeonbuk (6) & 59-955 & $55-2,100$ & $22-1,160$ & $0.19-1.89(0.71)$ & $0.18-1.40(0.59)$ \\
\hline $\begin{array}{l}\text { Chungnam, } \\
\text { Daejeon (3) }\end{array}$ & $46-131$ & $55-248$ & $23-139$ & $0.07-0.31(0.16)$ & $0.10-0.27(0.18)$ \\
\hline
\end{tabular}

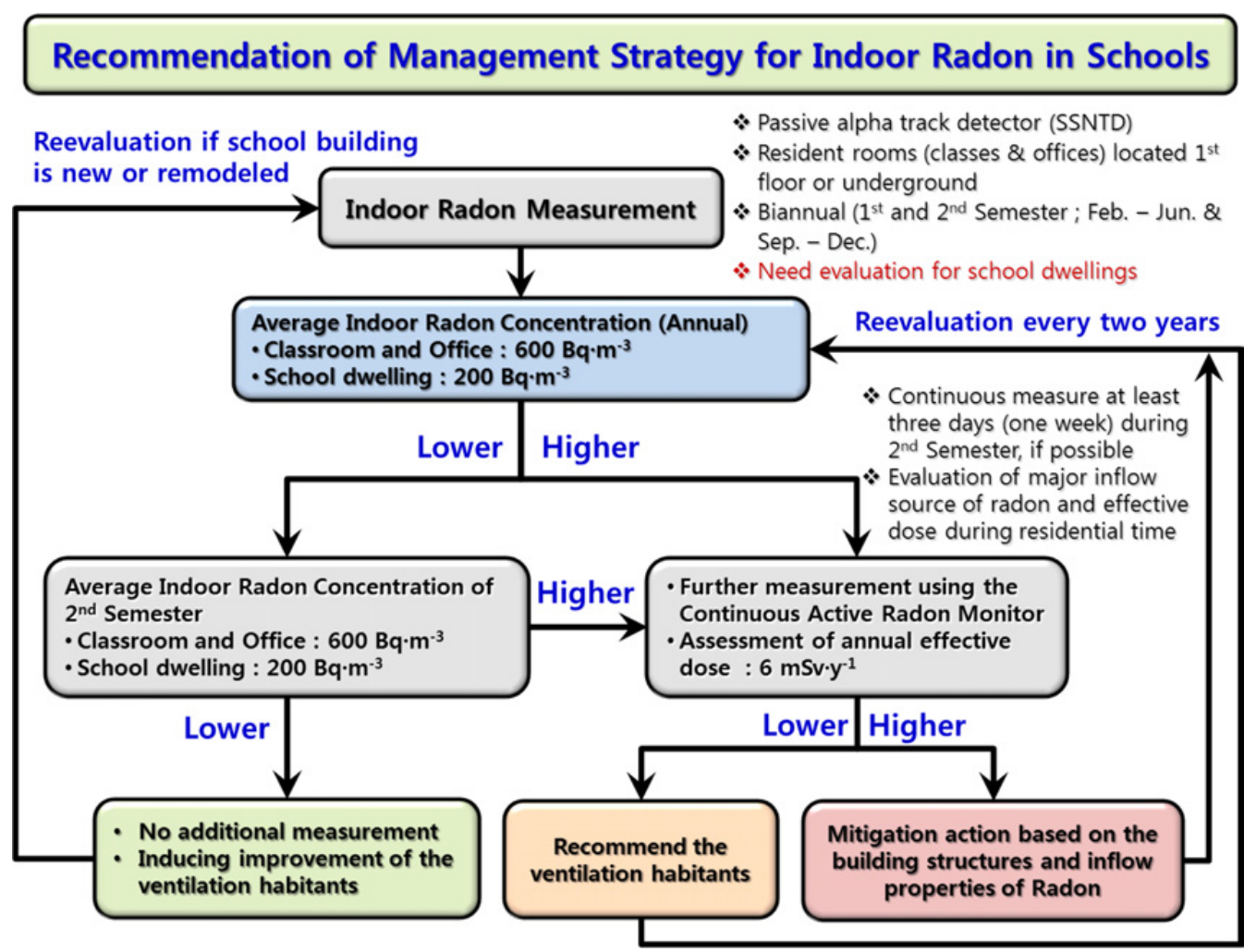

Figure 4. Recommendation of management strategy for indoor radon in schools.

where $E_{\mathrm{od}}$ is the effective dose of on duty time and $C_{\mathrm{o}}$ the on duty time weighted conversion factor.

Average radon concentration of the second semester was used as $R_{\mathrm{c}}$ and the working time based on the resident time of teachers and students in school were used as $R_{\mathrm{t}}$. Typical indoor value of 0.4 given in UNSCEAR 2000 report was used as $E_{\mathrm{f}}$ [5]. The value of $12 \mathrm{nSv} \cdot\left(\mathrm{Bq} \cdot \mathrm{m}^{-3} \cdot \mathrm{h}\right)^{-1}$ increased by the 
ICRP Statement on Radon in November 2009 [2] was applied to $D_{\mathrm{c}}$. The indoor radon concentration was increased in autumn and winter season, the effective doses was evaluated during the second semester only (about three months). The range of average radon concentration of schools and the evaluation results of effective dose were summarized in Table 1.

The results show that the effective doses due to inhalation of radon by teachers and students were insignificant during the occupancy time in school, except for several schools. The radon concentration of most schools could be significantly decreased by the simple change of the ventilation habitants. However, the several schools located near the granite area or the registered uranium mining lot area was found that the establishment of the physical mitigation plan of radon is necessary immediately. On the basis of preliminary results from epidemiological study conducting recently [6] and the average annual effective dose due to inhaled radon in Korea $(1.35 \mathrm{mSv})$ [7], number of 14 schools for requiring urgent mitigation action to lower the radon concentration and effective dose of on duty time were selected, and recommended to the Ministry of Education, Science, and Technology. In addition, management strategy for indoor radon in schools was recommended, as shown in Figure 4.

\section{CONCLUSION}

In order to estimate the exact effective doses to the public and workers in public building, radon concentration during working time is very important rather than the annual mean concentration measured by passive detectors. In the case of public buildings such as schools, continuous radon measurements and appropriate dose assessment are very important to justify the installation of mitigation systems for radon. The results of this study show that the radon removal during working time is sufficient by simply changing of ventilation habits such as opening of the windows early in the morning, except for some schools which show extremely high radon concentration. To manage the indoor radon at public buildings such as schools located in radon prone areas, more scientific and appropriate management protocols are needed to be developed.

\section{Acknowledgments}

This study was supported by the Nuclear Technology R\&D Program of the Ministry of Education, Science and Technology (MEST) in Korea. The authors are grateful to teachers and students for their approval and cooperation for the continuous monitoring about one week in each selected schools.

\section{References}

[1] Kim Y. J., Chang B. U., Park H. M., Kim C. K., and Tokonami S., National Radon Survey in Korea, Radiation Protection Dosimetry (2011), Accepted in press

[2] ICRP International Commission on Radiological Protection. ICRP Statement on radon, ICRP Committee release, Ref 00/902/09 (2009).

[3] Hubbard, L.M.; Hagberg, N.; Enflo, A. Temperature effect on radon dynamics in two Swedish dwellings, Radiation Protection Dosimetry 45 (1992) 381-386

[4] ICRP International Commission on Radiological Protection. Protection against Radon-222 at Home and Work. (ICRP Publication 65. Ann. ICRP 23/2, 1993).

[5] United Nations Scientific Committee on the Effects of Atomic Radiation, Exposures from natural radiation sources. UNSCEAR 2000 Report to the General Assembly, Annex B (UNSCEAR, 2000).

[6] Ha, M. N., Hwang S. S., Lee W. J., Jin Y. W., Geospatial analysis between residential radon exposure and lung cancer (Korea Institute Nuclear Safety, Korea, 2011) in Korean

[7] Korea Institute of Nuclear Safety, Assessment of Radiation Risk for the Korean Population (Korea Institute Nuclear Safety, Korea, 2007) in Korean 